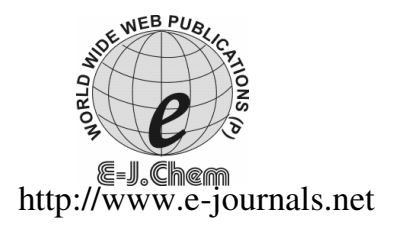

ISSN: 0973-4945; CODEN ECJHAO

E-Journal of Chemistry 2010, 7(1), 320-324

\title{
Spectrophotometric Determination of Lorsartan Potassium and its Dosage Form by Bromothymol Blue and Phosphate Buffer
}

\author{
L. LATHEESHJLAL*, P. PARTHIBAN, V. ALAGARSAMY, \\ M. SUNIL, J. VAIDHYA MAHUL and T. RAMA MOHAN \\ *Department of Pharmaceutics, Bharathi College of Pharmacy, \\ Bharathi Nagara, Mandya, Karnataka - 571422, India. \\ Department of Pharmaceutical Chemistry, \\ Dayananda College of Pharmacy, Bangalore, India. \\ latheesh18@rediffmail.com
}

Received 28 March 2009; Accepted 20 May 2009

\begin{abstract}
Simple, rapid and accurate, spectrophotometric method for the determination of losartan potassium by using bromothymol blue as a chromogen and phosphate buffer solution ( $\mathrm{pH} 3-4)$ as a diluting agent was developed. The developed colour shows maximum absorbance at $620 \mathrm{~nm}$ and it was observed that the absorbance of different dilution from the plots the calibration curve between the concentrations in $\mathrm{x}$-axis, absorbance at y-axis. The recovery studies were also carried out to ensure the reproducibility and repeatability. This recovery studies shows between $96.82-100.08 \%$ for the different formulation. Hence, it was concluded that the developed simple, precise and accurate method can be effectively used for the routine analysis of losartan potassium.
\end{abstract}

Keywords: Losartan potassium, Bromothymol blue, Phosphate buffer.

\section{Introduction}

Losartan potassium is an angiotensin II antagonist, chemically known as 2-butyl-4-chloro-1( $p$-(o-1H-tetrazole-5-yl-phenyl)-benzyl)-imidazole-5-methanol monopotassium salt and it has the molecular weight of 460.01 . Losartan potassium was previously assed by costly and complicated analysis technique like high equilibrium dialysis, HPLC, modulated scanning colorimetric and analysis the inhibitory effect of DUB 753 EXP 3174 on response to angiotensin II. It has less adverse effect when compared to other antihypertensive drugs, which blocking the action of angiotensin II of rennin angiotensin-aldosteron system. At presents there is no specific method for the estimation of losartan potassium by, spectrophotometric method. 
Analytical chemistry is a branch of chemistry that deals with the separation, identification and determination of components in a sample. It is the science of making quantitative measurements, which requires background knowledge of chemical and physical concepts ${ }^{1,2}$. Analytical instrumentation plays an important role in the production and evaluation of new products and in the protection of consumers and the environment. This instrumentation provides the lower detection limits required to assure safe foods, drugs, water and air $^{3}$.

Pharmaceutical analysis techniques are applied mainly in two areas ${ }^{4}$ i.e qualitative and qualitative analysis. Specific technologies and instrumentation in the recent and past are spectroscopic, electrochemical, chromatographic techniques etc. Many new techniques have been developed and at the same time the classic spectroscopic techniques have been modified to suit newer methods for the analysis of active principles.

\section{$U V$-Visible spectrophotometry}

The absorption of light by analytes is due to the presence of chromophores in their molecules, which are specific portions of molecules that can absorb radiant energy in the visible region. This method of analysis is based on measuring the absorption of monochromatic light by colored compounds in the visible path of the spectrum $(380-800 \mathrm{~nm})$. If the analytes are colorless, they are converted into colored compounds by reaction with a suitable chromogenic reagent. They must be stable and have a constant compositions and high color intensity. The photometric methods of analysis are based on Bouger-LambertBeer's Law, which establishes, the absorbance by a solution is directly proportional to the concentration of the analyte.

\section{Experimental}

Losartan potassium was received as a gift sample from Dr.Reddy's laboratory, Hyderbad. All other chemicals used were of analytical grade. Bromothymol blue, phosphate buffer were bought from Sd-fine chemicals. Dematerialized water was used throughout the work. Digital balance, systronics-117, UV-spectrometer, Jasco-410 FTIR spectrometer were used for this project.

\section{Preparation of standard solution}

Phosphate buffer solution (pH:3.4) was prepared by dissolving $5.04 \mathrm{~g}$ of disodium hydrogen phosphate and $3.01 \mathrm{~g}$ of potassium dihydrogen phosphate in water and made upto $1000 \mathrm{~mL}$.

Stock solution (1 $\mathrm{mg} / 1 \mathrm{~mL})$

$100 \mathrm{mg}$ of pure losartan potassium was accurately weighed and transferred into $100 \mathrm{~mL}$ volumetric standard flask and added phosphate buffer to dissolve the drug and made up to $100 \mathrm{~mL}$ with phosphate buffer.

\section{Bromothymol blue solution}

$50 \mathrm{mg}$ of bromothymol blue was dissolved in $4 \mathrm{~mL}$ of $0.02 \mathrm{M} \mathrm{NaOH}$ and $20 \mathrm{~mL}$ of ethanol (95\%). After solution is effected, sufficient water was added and made upto $100 \mathrm{~mL}$.

\section{Absorption spectra for drug in bromothymol blue}

From the stock solution, $10 \mathrm{~mL}$ was taken and added with $1 \mathrm{~mL}$ of bromothymol blue and it was diluted with $500 \mathrm{~mL}$ of phosphate buffer to make the concentration $200 \mu \mathrm{g} / \mathrm{mL}$. The absorbance of the solution was measured between $400-800 \mathrm{~nm}$. 


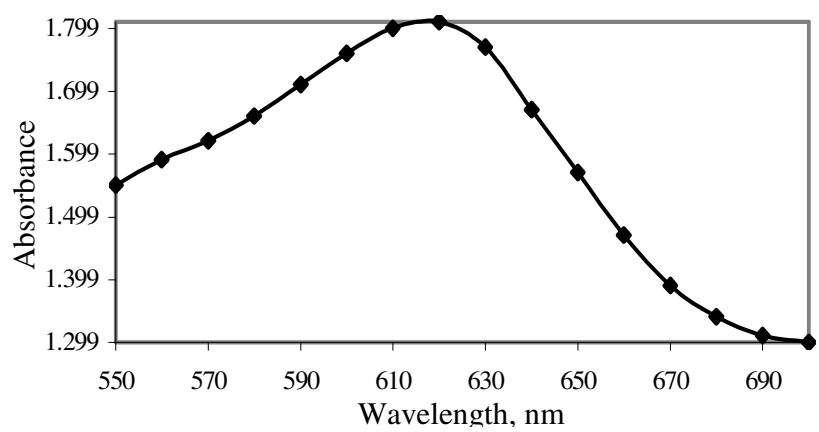

Figure 1. Absorbance obtained from different wavelength.

\section{Preparation of standard graph}

According to Beer's law, the graph was drawn by measuring the absorbance of various concentration of drug solution against the blank from stock solution $(1 \mathrm{mg} / \mathrm{mL})$ of various concentrations $0.5 \mathrm{~mL}, 1 \mathrm{~mL}, 1.5 \mathrm{~mL}, 2 \mathrm{~mL}$, and $2.5 \mathrm{~mL}$ were pipette out and transferred into $100 \mathrm{~mL}$ of volumetric flask and make up with phosphate buffer. The drug concentration in each flask was $5 \mu / \mathrm{mL}, 10 \mu / \mathrm{mL}, 15 \mu / \mathrm{mL}, 20 \mu / \mathrm{mL}$ and $25 \mu / \mathrm{mL}$ respectively. Absorbance of each solution was observed and the calibration graph was drawn by plotting the concentration against absorbance (Figure 2).

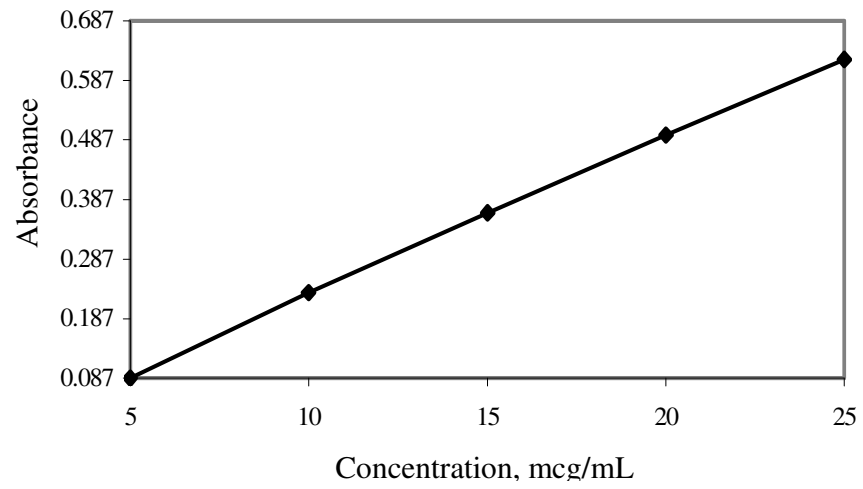

Figure 2. Calibration curve for losartan potassium using phosphate buffer as a blank.

\section{Effect of reagent concentration}

The effect of reagent concentration was done by using different reagent concentration and this $1 \mathrm{~mL}$ of $1 \mathrm{~N}$ bromothymol blue was found to be the minimum effect concentration. The concentration less than $1 \mathrm{~N}$ bromothymol blue and less than $1 \mathrm{~mL}$ of reagent give the deviation in the curve.

\section{Stability of colour}

The colour changes from yellowish orange to green shows the completion of reaction with bromothymol blue. Then the stability of colour was studied by measuring the absorbance for every 10 minutes and it has no colour changes and no change in the absorbance up to $1 \mathrm{~h}$. 


\section{Analysis of formulation and recovery studies}

Three different brands of losartan potassium tablets were taken for analysis. They are covance- $25 \mathrm{mg}$, losar-50 mg and repace- $25 \mathrm{mg}$ and the tablets were powdered gently in a glass mortar. The tablet powder equivalent to $10 \mathrm{mg}$ of losartan potassium was weighed and transferred to $100 \mathrm{~mL}$ volumetric flask. Then phosphate buffer was added as a solvent to dissolve the drug content and made up to $100 \mathrm{~mL}$.

The solution was filtered by using whattmann filter paper. From that $1 \mathrm{~mL}$ of filtrate was pipette out and transferred into a $100 \mathrm{~mL}$ volumetric flask along with $1 \mathrm{~mL}$ of bromothymol blue and made up to $100 \mathrm{~mL}$ with phosphate buffer. The absorbance was measured at $620 \mathrm{~nm}$ against mixture of bromothymol blue and phosphate buffer for each brand of tablet. The amount of drug present in the solution was calculated and shown in Table 1

Table 1. Analysis of losartan potassium in formulation.

\begin{tabular}{ccccc}
\hline S.No & $\begin{array}{c}\text { Name of } \\
\text { formulation }\end{array}$ & $\begin{array}{c}\text { Labeled amount } \\
\mathrm{mg} / \text { tablet }\end{array}$ & $\begin{array}{c}\text { Amount } \\
\text { found }{ }^{*} \mathrm{mg}\end{array}$ & $\begin{array}{c}\text { Percentage label } \\
\text { claim* }^{*} \%\end{array}$ \\
\hline 1 & Covance & 25 & $24.86 \pm 0.05$ & $99.44 \pm 0.24$ \\
2 & Losar & 25 & $25.08 \pm 0.01$ & $100.37 \pm 0.06$ \\
3 & Reopace & 25 & $24.77 \pm 0.03$ & $99.08 \pm 0.86$ \\
\hline
\end{tabular}

The recovery studies experiments were performed for the same three brands of tablets (Covance, Losar and Repace) and calculated recovery studies by the following formula,

Percentage of recovery $=[\mathrm{b}-\mathrm{a} / \mathrm{c}] \times 100$

Where, $\mathrm{a}=$ Amount of sample drug

$\mathrm{b}=$ Amount of sample drug + standard drug

$\mathrm{c}=$ Amount of sample drug added.

The results of the recovery studies are shown in Table 2.

Table 2. Analysis of losartan potassium in recovery studies.

\begin{tabular}{ccccc}
\hline S.no & $\begin{array}{c}\text { Name of } \\
\text { formulation }\end{array}$ & $\begin{array}{c}\text { Labeled amount } \\
\mathrm{mg} / \text { tablet }\end{array}$ & $\begin{array}{c}\text { Amount } \\
\text { found, } \mathrm{mg}\end{array}$ & $\begin{array}{c}\text { Percentage of } \\
\text { recovery studies, \% }\end{array}$ \\
\hline 1 & Ovance & 25 & $25.02 \pm 0.01$ & $100.08 \pm 0.06$ \\
2 & Losar & 25 & $24.20 \pm 0.05$ & $96.80 \pm 0.42$ \\
3 & Eopace & 25 & $24.68 \pm 0.02$ & $98.60 \pm 0.70$ \\
\hline
\end{tabular}

\section{Results and Discussion}

A simple, rapid and accurate spectrophotometric method was developed for the estimation of losartan potassium using bromothymol blue. The wavelength selected for analysis was $620 \mathrm{~nm}$ where the absorbance for the drug is maximum. The spectra and calibration curve were obtained for losartan potassium in the range of $5-25 \mu \mathrm{g} / \mathrm{mL}$. The recovery studies were also carried out to ensure the reproducibility and repeatability of the method of adding known amount of standard drug solution. The reports of formulation and recovery studies are given in Table 2.

\section{Conclusion}

The method is specific and there were no interference firm additives and impurities and the low standard deviation values ensure the reliability of the method. The amount of drug obtained is in good agreement with labeled claim. Hence it is concluded that the developed simple, precise and accurate method can be effectively used for the routine analysis of losartan potassium. 


\section{References}

1. Kasture A V, Pharmaceutical analysis; $12^{\text {th }}$ Ed., Nirali prakashan, Pune, India, 2007, 1, 1-2.

2. Sharma B K, Instrumental methods of chemical analysis, In; Introduction to Analytical Chemistry, $23^{\text {th }}$ Ed., Goel Publishing House, Meerut, 2004, 1-4.

3. Basic Education in Analytical Chemistry, Analytical Science, 2001, 17(1).

4. Willard H H, Merritt L L, Dean J J A and Frank A S, Instrumental method of analysis; $7^{\text {th }}$ Ed. CBS Publishers and Distributors, New Delhi, 1986, 321-23

5. Sethi P D, Quantative analysis of drugs in pharmaceutical formulation, $3^{\text {rd }}$ Ed, 1-21, 51- 56.

6. Galan W E, Instrumental methods of chemical analysis, $5^{\text {th }} \mathrm{Ed}, 1$.

7. Cao H and Oldenburg K R, J Pharm Biomed Anal., 2001, 24, 603-611.

8. $\quad$ Erk N, J Pharm Biomed Anal., 1999, 21, 339-345.

9. $\quad$ Rabel S R and Jona J A, J Chromatogr B Biomed Sci Appl., 1997, 19, 374-378.

10. Fathing D and Sioa D, J Med Chem., 1993, 36, 1230- 1238.

11. Osei S Y and Minces R K, J Pharm Sci., 2001, 90, 580-587. 


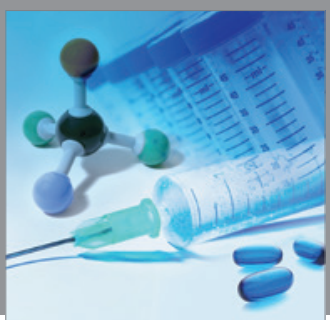

International Journal of

Medicinal Chemistry

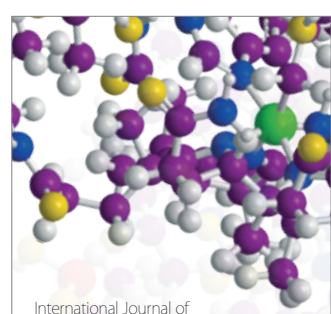

Carbohydrate Chemistry

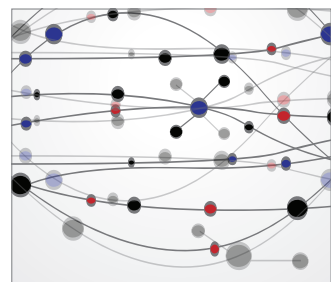

The Scientific World Journal
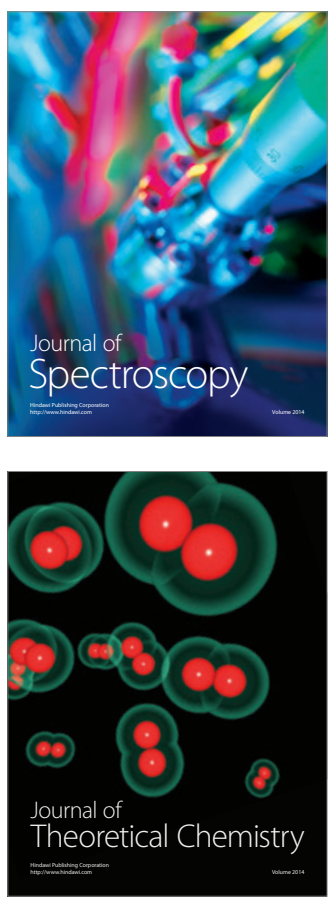
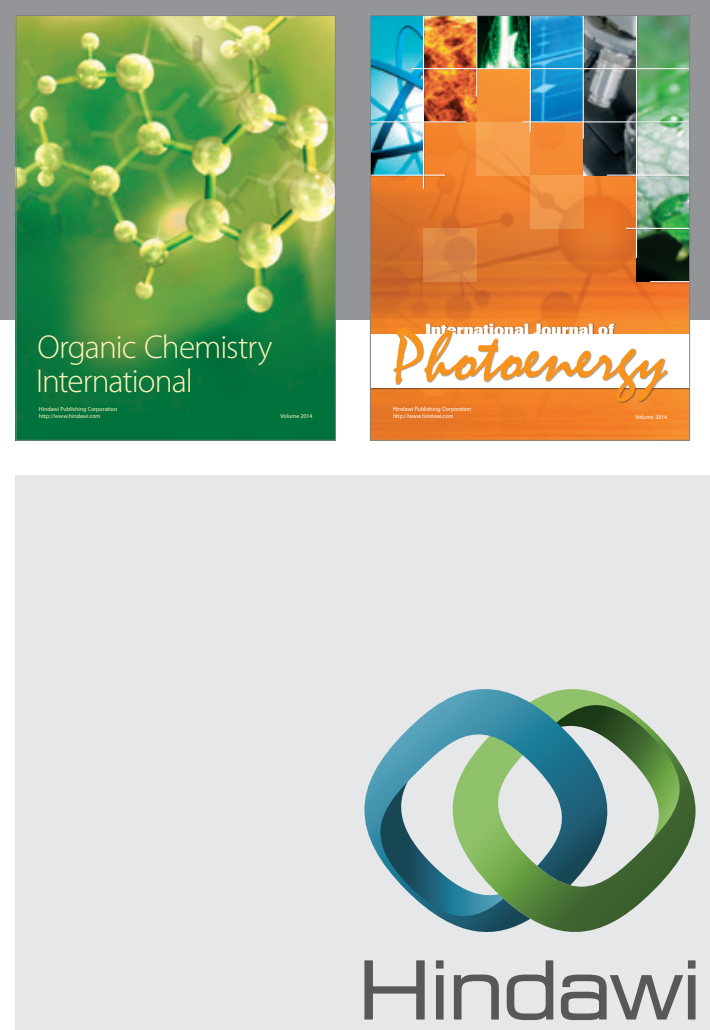

Submit your manuscripts at

http://www.hindawi.com
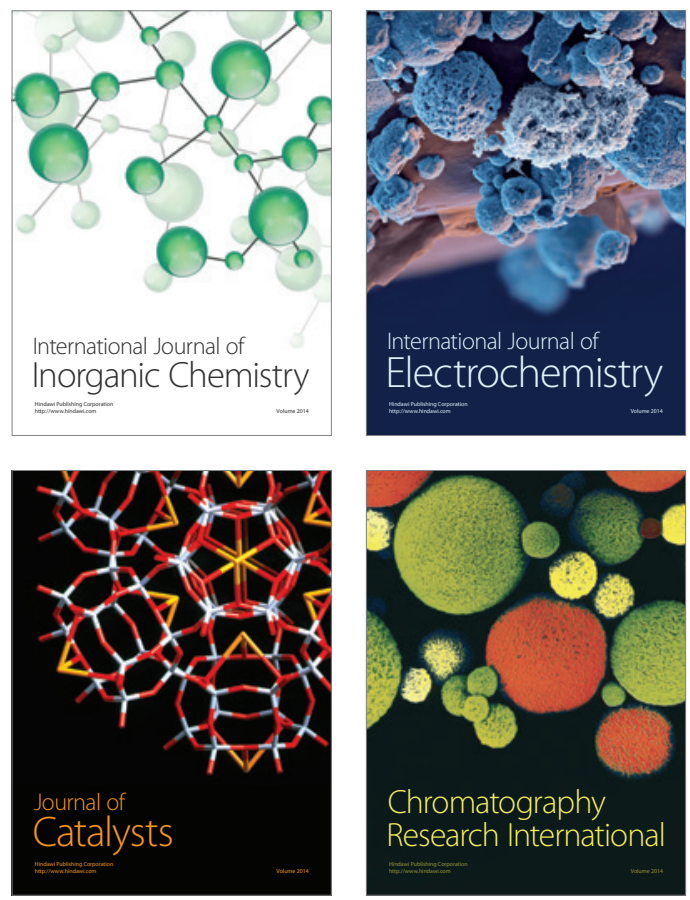
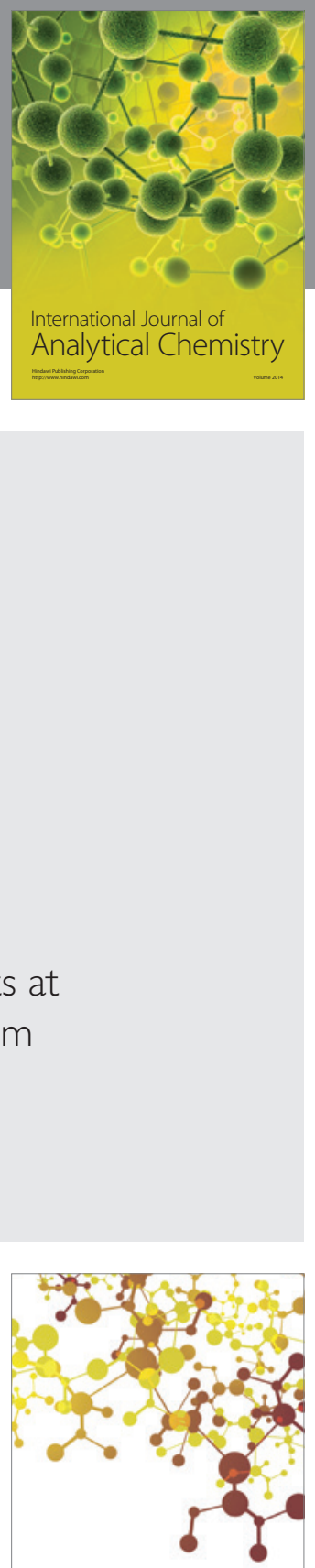

Journal of

Applied Chemistry
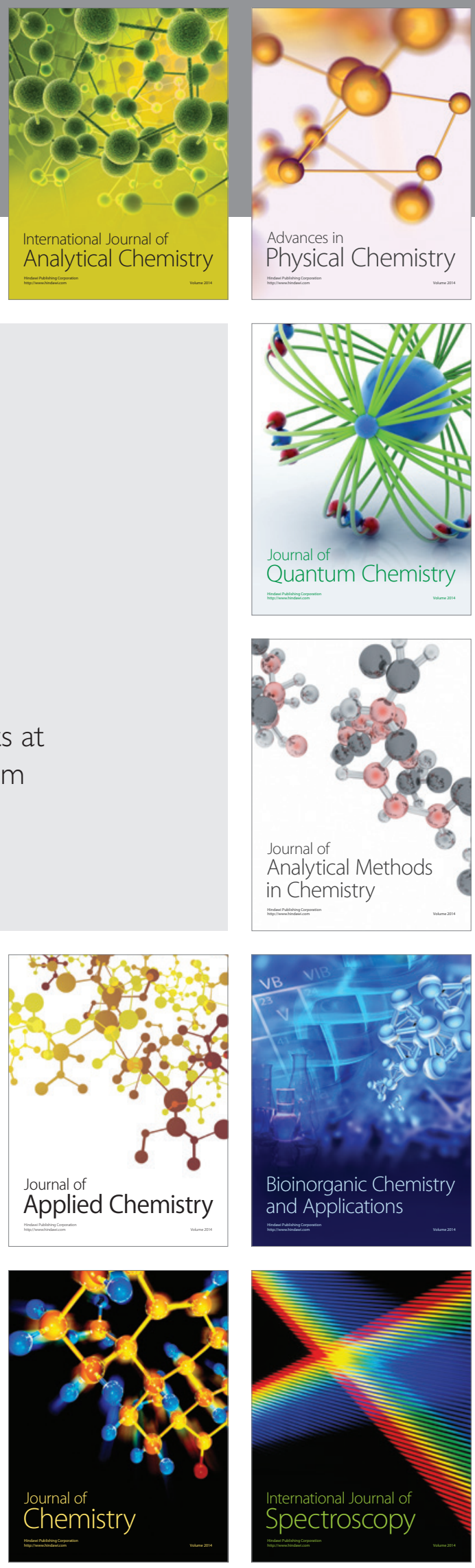